\section{Responsabilidade do Estado pelo racismo institucional nos atendimentos obstétricos realizados no Sistema Único de Saúde}

\author{
Siqueira, Diana ${ }^{1}$ \\ Pimentel, Willian ${ }^{1}$ \\ Sarsur, Marcelo ${ }^{1}$ \\ Dadalto, Lucina ${ }^{1}$
}

\section{${ }^{1}$ Grupo de Estudos e Pesquisa em Bioética do Centro Universitário Newton Paiva - GEPBio. Contato: diana.siqueira@outlook.com}

PALAVRAS CHAVE: racismo institucional; violência obstétrica; direito à saúde; sistema único de saúde (SUS).

O objetivo do presente trabalho é verificar a possibilidade de responsabilizar objetivamente o Estado pela prática de racismo institucional no contexto dos atendimentos obstétricos a mulheres negras no Sistema Único de Saúde (SUS). Para tanto é imprescindível elucidar o conceito e consequentemente o sistema de desigualdade estabelecido em decorrência desse fenômeno comportamental e social. O termo foi criado por Stokely Carmichael e Charles Hamilton em 1967. Segundo esses autores o racismo institucional é a falha coletiva de uma organização em prover um serviço apropriado e profissional às pessoas por causa de sua cor, cultura ou origem étnica, recentemente. No Brasil, a Política Nacional de Saúde Integral da População Negra, pelo Ministério da Saúde em 2013, o definiu como a produção sistemática da segregação étnico-racial, nos processos institucionais, reiterando que ele se manifesta por meio de normas, práticas e comportamentos discriminatórios adotados no cotidiano de trabalho, resultantes de ignorância, falta de atenção, preconceitos ou estereótipos racistas, colocando pessoas de grupos raciais ou étnicos discriminados em situação de desvantagem no acesso a benefícios. Uma pesquisa divulgada pela Política Nacional de Atenção Integral à Saúde da Mulher, em 2009, evidencia esse racismo: $11,1 \%$ de mulheres negras não receberam anestesia no parto normal, enquanto a taxa para mulheres brancas foi de apenas $5,1 \% ; 62,5 \%$ da mulheres negras receberam orientação sobre a importância do aleitamento materno, enquanto $77,7 \%$ das mulheres brancas foram orientadas; $27,0 \%$ das mulheres negras tiveram um acompanhante no parto, enquanto $46,2 \%$ das mulheres brancas exerceram o mesmo direito. Isso posto, a pesquisa que ora se apresenta justifica-se pela discrepância entre o tratamento concedido a mulheres brancas e negras nas mesmas condições. Para tanto, utilizou-se como método a pesquisa teórica de natureza exploratória, com levantamento bibliográfico e documental na seara jurídica e bioética, tendo por base estudos históricos acerca da escravidão e sua repercussão para a sociedade brasileira contemporânea, notadamente no âmbito da relação obstetra-parturiente. Conclui-se, portanto, que o Estado possui responsabilidade civil objetiva frente à prática da violência obstétrica racial, uma vez que esta é resultado direito do racismo institucional, sendo necessárias ações bioéticas e jurídicas para que o Estado possa mitigar essa prática.

AGRADECIMENTOS. Agradecemos a todos que de alguma forma contribuíram para a realização desta pesquisa, mesmo com toda a dificuldade encontrada para produção acadêmica científica nesse país. Em especial aos Coordenadores do GEPBio, por acreditarem no nosso potencial.

\section{REFERÊNCIAS:}

[1] WERNECK, Jurema. Racismo institucional e saúde da população negra. Saude soc. [online]. 2016, vol.25, n.3, pp.535-549. ISSN 0104-1290. Disponível em: $<$ http://dx.doi.org/10.1590/s0104-129020162610 >, acesso em 20 set. 2018.

[2] SANTOS, G., M. Silva (eds.) Racismo no Brasil: Percepções da Discriminação e do Preconceito Racial no Século XXI, São Paulo: Editora Fundação Perseu Abramo, 2005.

[3] BRASIL. Governo Federal. Parto do Princípio - Mulheres em Rede Pela Maternidade Ativa. Violência Obstétrica. "Parirás Com Dor". Brasil, 2012. Disponível em: $<$ https://www.senado.gov.br/comissoes/documentos/SSCEPI/D OC\%20VCM\%20367>.pdf, acesso em 02 set. 2018.

[4] PARANHOS, D. O papel da bioética no enfrentamento do racismo. In: Revista Brasileira de Bioética, v. 12, p. 1-11.

[5] CARMICHAEL, S; HAMILTON, C. Black power: the politics of liberation in America. New York, Vintage, 1967, p. 4. 